Bolm. Zool., Univ. S. Paulo

$2: 183-187,1977$

\title{
NOTAS SOBRE ASSOCIAÇOES DE Trigona (Oxytrigona) tataira (Apidae, Meliponinae)
}

\author{
MARILDA CORTOPASSI-LAURINO \\ Departamento de Zoologia do Instituto de Biociencias da Universidade de São Paulo
}

ABSTRACT

The relationships between stingless bees and other arthropods are quite extensive. In this work associations of Oxytrigona tataira with Membracoidea were observed; the bees collected and dehydrated honeydew in the same place. It was also observed that the wax-substanc? covering the eggs of the same Membracoidea is collected by these bees.

\section{RESUMO}

As relações entre abelhas sem ferrão e outros artrópodos são bastante variáveis. Nesse trabalho são descritas associações de Oxytrigona tataira com Membracoidea através das quais as abelhas induzem a eliminação de liquido e desidratam-no no próprio local. A substancia cerosa que recohre e desova dos mesmos Membracoidea também é coletada por essas abelhas.

\section{INTRODUC̣AO}

As relaçōes entre abelhas sem ferrão e outros artrópodos são bastante diversificadas e conhecidas desde o século passado. A contribuição inicial mais notável desse tema foi a de GERARD (1874 apud SALT 1929) que nāo só descobriu um interessante besouro melitófilo Scotocryptus meliponae como também mencionou a presença de Isopoda, Diptera, Lepidoptera e formigas dentro de ninhos de Meliponineos. Mais recentes são os trabalhos que dão ênfase às assoriações entre abelhas e termitas.

SALT (1929:445), fazendo um retrospecto das relações entre as abelhas sem ferrāo e outros artrópodos, encontrou referências a 11 ordens de artrópodos. Esses trabalhos foram suficientes para permitir a classificação de 26 familias e 29 gêneros; excluindo simples anotações sobre relações mutualísticas das abelhas Meliponinae; existem 44 associaçōes especificamente definidas, muitas das quais não relacionadas com os ninhos

Quanto às associações de abelhas sem ferrão com membracideos, MỨLLER (1873:201) estudou Trigona cagafogo (Oxytrigona tataira), encontradas servindo-se de larvas de membracídeos Potnia indicator (?) em Cassia multijuga. SILVESTRI (1902:152) observou Trigona cupira servindo-se de Aethalion reticulatum e COCKERELL (1920 apud SALT 1929) menciona Trigona amalthea visitando a mesma espécie. LAROCA \& SAKAKIBARA (1976:71) verificaram no cerrado pró- 
ximo de Campo Grande, Mato Grosso, operárias de Trigona hy'alinata branneri visitando galhos de Luhea speciosa (Tiliacea) onde ocorriam colônias de Aconophora flavipes (Membracidae) em vários estágios de ninfas e adultos. As abelhas andavam sobre os membracideos e ocasionalmente lambiam a porção terminal do abdômen das ninfas. CASTRO (1975:573) observou interaçōes mutualísticas em colônias de Aethalion reticulatum com formigas do gênero Camponotus durante a noite e dos mesmos Homoptera com Trigona spinipes durante o dia. Espécies diferentes de formigas podem se alternar nas associações com Aethalion reticulatum sendo as Camponotus sericeiventris observadas durante o dia enquanto que as Camponotus tanaemyrmex durante o dia e a noite, porém nunca na presença de sericeiventris (BROWN. 1976:105̄)

\section{MATERIAL E MÉTODOS}

As observações foram feitas no Banco Biológico dos Micos-Leões, junto ao Parque Nacional da Tijuca no Estado do Rio de Janeiro, durante períodos irregulares nos meses de abril, maio e outubro de 1975.

Algumas abelhas foram marcadas no tórax com tinta à base de nitrocelulose.

O método de estudo constituiu de observacão direta e anotações correspondentes.

\section{RESULTADOS E DISCUSSÃO}

Observei pela primeira vez em 22/4/1975, num único exemplar de curindiba (Trema micrantha - Ulmacea), centenas de abelhas indigenas Oxytrigona tataira andando sobre agregados de larvas de Enchophylum quinquemaculatum Fairmaire, 1846 (Membracidae) e alguns adultos de Aethalion reticulatum Linnaeus, 1767 (Aethalionidae), ambos de superfamilia Membracoidea.

Essas abelhas caminhavam sobre os agregados de larvas, tocando-lhes o corpo com as antenas. As larvas, às vezes, expunham nesse momento, a parte final do seu aparelho digestivo e eliminavam uma ou mais gotas de liquido transparente, que eram imediatamente lambidas pelas abelhas. Estas continuavam tocando as mesmas larvas com as antenas até que elas eliminassem outras gotas; porém, quando tal fato não acontecia, a abelha passava para a larva seguinte. Ao mesmo tempo que solicitavam a secreção aos membracideos, as abelhas podiam desidratar. Entretanto, outras abelhas ficavam somente desidratando. sem a coleta simultânea da secreção. (fig. 1)

Individuos adultos de Aethalion reticulatum que também se encontravam nos ramos do exemplar de corindiba, eram visitados pelas abelhas Oxytrigona tataira. Foi observado que estas abelhas tocavam várias vezes com as antenas todo o corpo do homóptero, porém com maior frequência a parte posterior. Como no caso anterior, quando o homóptero eliminava a goticula de liquido, esta era lambida pela abelha. Além de associarem-se com abelhas, adultos de Aethalion reticulatum "podem viver em simbiose com Camponotus crassus e $C$. brasiliensis entre outros" (COSTA LIMA, 1968:99).

Deve-se salientar que não é comum operárias de meliponideos desidratarem fora da colméia. Em Oxytrigona tataira já foram observadas abelhas desidratando 


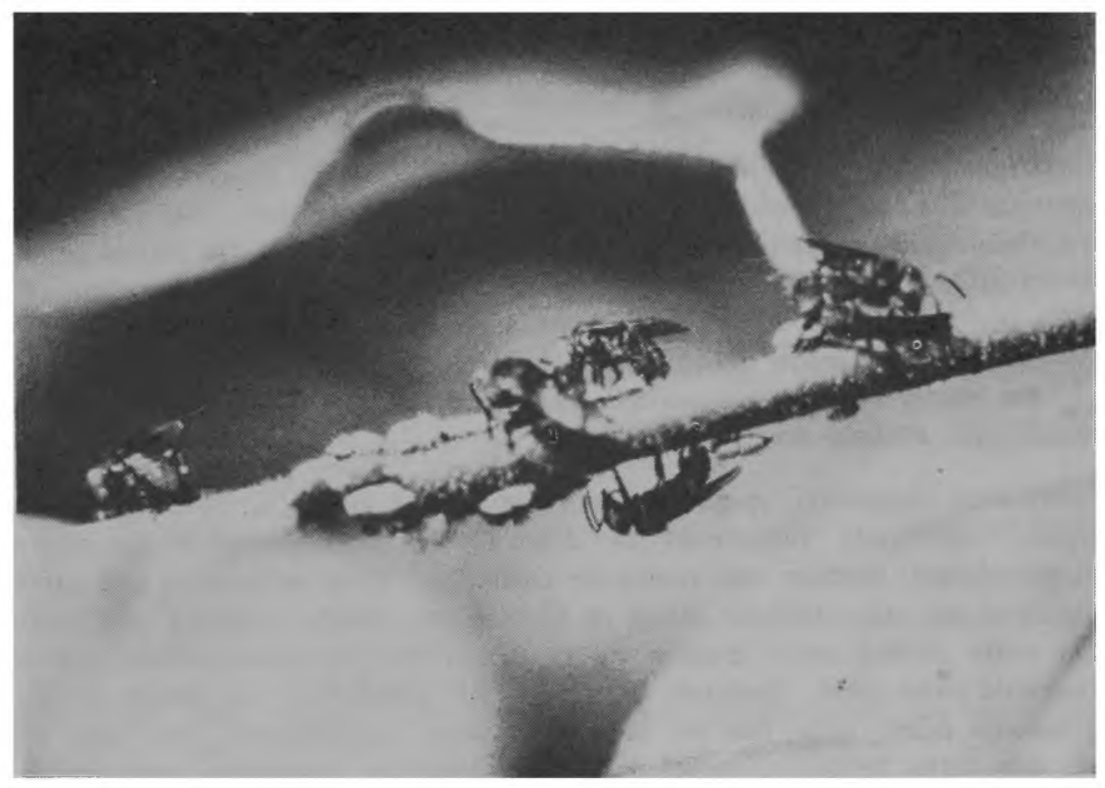

Fig. 1. Oxytrigona tataira desidratando e solicitando liquido às larvas de Enchophylum quiriquemaculatum 
sobre flores de bananeira (Musacea) em Blumenau, SC, por Nogueira-Neto e Imperatriz Fonseca (inf. pessoal). Nogueira-Neto (inf. pessoal), também observou em Itanhaem, SP. operárias de Trigona spinipes desidratando sobre flores de coqueiro.

O fato dessas abelhas desidratarem no local de coleta do liquido é bastante interessante, pois: a - significaria uma economia de energia por parte da abelha, pois ela só retornaria à colméia quando estivesse com o papo repleto de mel para então armazená-lo. b - manteria o interior da colônia com menor teor de umidade. c - indicaria que a atividade de desidratar o néctar seria efetuada na mesma época que a coleta externa.

Em Oxytrigona tataira, foram observadas essas atividades em temperaturas que variaram de $15^{\circ} \mathrm{C}$ a $32^{\circ} \mathrm{C}$ e num intervalo de tempo que correspondia aproximadamente a desde uma hora após o amanhecer até meia hora antes do anoitecer, sugerindo que essas abelhas realizem suas atividades externas dentro de extensos intervalos de tempo e tempartura.

Oxytrigona tataira mantém um certo território; isso é sugerido pelo fato de que algumas abelhas, marcadas e soltas nas proximidades $(3 \mathrm{~m})$, voltavam ao local de onde tinham sido retiradas (folha ou aglomerado de larvas). Se depois de soltas pousavam próximas ao local de origem, podiam chegar até ele pela própria planta ou então por novo vôo. Além disso, investiam contra qualquer inseto que ai tentasse pousar, mesmo sendo indivíduos da própria espécie. Entre os outros insetos que vinham coletar liquido na superfície das folhas, foram observados vários Diptera e abelhas como Plebeia droryana.

Outro fato observado, apesar de mais raro, foi a coleta da substância branca, gelatinosa, encontrada recobrindo as desovas dos membracídeos Enchophylum quinquemaculatum, também nos ramos de curindiba. Essa substância era carregada nas corbículas das abelhas. Além de Oxytrigona tataira, coletava esse material também outra abelha muito comum na região, Tetragonisca angustula, conhecida popularmente como jataí. Segundo COSTA LIMA (1942:53), "as fêmeas de alguns membracídeos põem ovos uns ao lado dos outros cobrindo-os com uma massa branca, um tanto pegajosa, secretada pelas glândulas coletéricas, geralmente de consistência cérea". As abelhas devem coletar esse material oor ser de natureza cérea. MARQUES (1928:19), observou Melipona ruficrus Latreile usando suas mandibulas para retirar porções da massa que cobrem os ovos de Aethalion reticulatum sem dano aparente para os mesmos.

Deve-se observar que em inicios de outubro, o espécime de curindiba observado já se apresentava em péssimas condições, quase sem folhas. Mesmo assim, nos poucos ramos jovens e com folhas, foram anotadas atividades de membracideos e de Oxytrigona tataira.

\section{CONCLUSÕES}

Através desse trabalho foi constatado que:

1. Oxytrigona tataira pode induzir membracideos e eliminarem liquido originado da sucção de seiva vegetal. Esse liquido é lambido pela abelha e pode ser desidratado no próprio local 
2. Oxytrigona tataira, nesse caso. mantém território investindo até contra abelhas da mesma espécie.

3. Oxytrigona tataira pode coletar substância cerosa que recobre as desovas dos membracideos observados. transportando-a em suas corbículas.

\section{AGRADECIMENTOS}

A autora expressa seus agradecimentos aos Sr. Dr. Nilo dos Santos e Sr. José Pinto F'onseca pela identificação do material e aos Dr. Alceo Magnanini e Dra. Vera Lucia I. Fonseca pela leitura e crítica do texto. (Pr. 2833/74).

\section{REFERÊNCIAS BIBLIOGRÁFICAS}

BROWN, R. L., 1976 - Behavioral observations on Aethalion reticulatum (Hem, Aethalionidae) and assuciated ants. Insectes Sociaux :33 (2): 99-107.

COSTA LIMA, A. M., 1942 - Insetos do Brasil. Escola Nacional de Agronomia. Rio de Janeiro, 3: 327 pp.

COSTA LIMA, A. M.. 1968 - Quarto Catälogo dos Insetos que vivem nas plantas do Brasil - seus parasitos e predadores. Ministério da Agricultura. Rio de Janeiro, 2 (2): 622 pp.

LAROCA, S. \& A. M. SAKAKIBARA, 1976 -- Mutualismo entre Trigona hyalinata branneri (Apidae) e Aconophora flavipes (Membracidae). Rev. Bras. Ent. 20 (2): 71-72.

MARQUES, A., 1928 - Cigarrinha nociva a várias espécies de vegetais. Bol Inst. biol. Def. agricola. Rio de Janeiro, 6: 1-27.

Mt:LLER, H., 1873 - Larvae of Membracis serving as milk-cattle to a Brazilian species of Honey-bees. Nature 8: 201-202.

SALT, G., 1929 - A contribution to the ethology of Meliponinae. Trans. ent. Soc. London, 77 (2): 431-470.

SILVESTRI, F., 1902 - Constribuzione alla conoscenza dei Meliponidi del bacino del Rio de la Plata. Rev. Patol. Ver. 10: 121-174. 
